\title{
MÍDIA E PRODUÇÃO DE SENTIDOS SOBRE "PATRIMÔNIO" EM SÃO LUÍS DO MARANHÃO*
}

\author{
MEDIA AND PRODUCTION OF SENSES OF "HERITAGE" \\ IN SAO LUÍS CAPITAL OF MARANHÃO STATE
MEDIOS DE COMUNICACIÓN Y PRODUCCIÓN DE SENTIDOS DEL TÉRMINO PATRIMONIO EN SÃO LUÍS DE MARANHÃO

Conceição de Maria Belfort de Carvalho

\begin{abstract}
Resumo: A mídia é um dos mais eficientes lugares discursivos em que se produzem identidades. Este artigo verifica, a partir da Analise do Discurso de base foucaultiana, as formas como o discurso midiático articula um jogo de produção de sentidos do conceito de patrimônio em São Luís-Ma, por meio de excertos do jornal O Estado do Maranhão e O Imparcial.
\end{abstract}

Palavras-chave: Patrimônio cultural. Discurso. Mídia.

\begin{abstract}
The media is one of the most efficient discursive places in which identities are produced. This article examines, from the base of Foucault's Discourse Analysis, the ways in which media discourse articulates a set of production of meanings of the concept of heritage in Sao Luis-Ma, through excerpts from two local newspapers O Estado do Maranhão and O Imparcial.
\end{abstract}

Keywords: Cultural heritage. Discourse. Media.

Resumen: Los medios de comunicación son considerados uno de los campos discursivos más eficaces para la producción de identidades. Teniendo en cuenta dicha afirmación, este artículo examina, desde la perspectiva del Análisis del Discurso de orientación foucaultiana, las maneras como los discursos mediáticos articulan un juego de producción de significados del concepto del término "patrimonio" en São Luís-Ma, a través de extractos de los periódicos locales O Estado do Maranhão y O Imparcial.

Palabras clave: Patrimonio cultural. Discurso. Medios de comunicación.

\section{INTRODUÇÃO}

O discurso midiático exerce sobre a sociedade de consumo um poder coercitivo. Tal poder tem com objetivo a formação de valores e opiniões por meio de mecanismos como a propaganda e o marketing. A capacidade de investigar, de ser um instrumento imparcial da divulgação e informação dos fatos deixa, aos poucos, de ser prioridade nos meios de comunicação. A mídia configura-se no campo da disputa pela hegemonia, sendo vista como uma aliança entre tecnologia, comunicação e capital. No Maranhão, por exemplo, ela apresenta-se como uma aliança entre tecnologia, comunicação e política, não voltada simplesmente para a produção de lucros, mas para a fomentação de votos eleitorais. Nessas condições, emerge um discurso fundamentado no jogo de interesses que visa a legitimar uma ideologia dominante.

Particularmente na contemporaneidade, devido ao seu alcance social e à dimensão desse alcance, a mídia é um dos mais eficientes lugares discursivos em que se produzem sentidos e identidades. No processo de preservação do patrimônio, em determinado momento a demarcação da realidade é operacionalizada por meio da separação de "objetos" que serão categorizados como patrimônio, de onde decorre a necessidade de preservar, criar identidade e, não apenas isso, mas preservar e criar identidade de forma sustentável.

Iremos verificar a ação discursiva da mídia, em enunciados de matérias publicadas em dois jornais de circulação local: jornal O Estado

\footnotetext{
*Artigo recebido setembro 2012

Aprovado em dezembro 2012
} 
do Maranhão e jornal O Imparcial, ambos de 1997, ano em que São Luís recebeu o título de Patrimônio Cultural da Humanidade. Para desenvolver as análises apresentamos uma breve discussão sobre o processo de fragmentação da identidade do sujeito e alguns conceitos da teoria do discurso de Michel Foucault, como a relação entre discurso e poder, verificando de que forma tais conceitos operam na constituição do sentido de patrimônio.

\section{DISCURSO, MÍDIA E PRODUÇÃO DE SENTIDOS NA CAPITAL PATRIMÔNIO CULTURAL DA HUMANIDADE}

A pergunta "quem somos nós" traz para discussão o papel do sujeito na sociedade. $\mathrm{Na}$ pós-modernidade o sujeito é edificado na diversidade de culturas do mundo globalizado e tem sua identidade construída e reconstruída permanentemente ao longo de sua existência, vivendo um constante processo de identificação.

Desde que o sujeito foi reconhecido como entidade descentrada, no final do século XIX, há uma permanente (re)constituição das identidades, que, por sua vez, está relacionada a um jogo de poderes (FOUCAULT, 2001). E o principal veículo da produção de identidades, segundo Foucault, é o discurso, enquanto dispositivo de enunciação.

Segundo Foucault (1986), para analisarmos o discurso precisamos desconsiderar as explicações unívocas, a busca do sentido último ou do sentido oculto das coisas. É preciso ficar simplesmente no nível de existência das palavras, das coisas ditas. Isso significa que é preciso trabalhar arduamente com o próprio discurso, deixando-o aparecer na complexidade que lhe é peculiar, dando conta de relações históricas, de práticas muito concretas, que estão "vivas" nos discursos.

Foucault (1986, p. 135-136) concebe o discurso como um complexo de enunciados, na medida em que se apóiem na mesma formação discursiva. Ele é constituído de um número limitado de enunciados, para os quais podemos definir um conjunto de condições de existência, por isso, ele "é, de parte a parte, histórico - fragmento de história, unidade e descontinuidade na própria história, que coloca o problema de seus próprios limites, de seus cortes, de suas transformações, dos modos específicos de sua temporalidade".

O discurso é um conjunto de enunciados e os enunciados são performances verbais e não verbais em função enunciativa, daí decorre a ideia de "prática", prática discursiva, ou seja, "[...] um conjunto de regras anônimas, históricas, sempre determinadas no tempo e no espaço, que definiram, em uma dada época e para uma determinada área social, econômica, geográfica ou lingüística as condições de exercício da função enunciativa" (FOUCAULT, 1986, p. 136).

Podemos perceber que a função enunciativa que enreda o discurso do patrimônio (e seu complexo) surge num tempo determinado (e em suportes materiais, tais como os jornais) e daí se pode perguntar sobre sua emergência e suas consequências, sendo uma delas a outorgação do título de Patrimônio Cultural da Humanidade para a cidade de São Luís, desfecho de um processo que ocorre em virtude da mobilização de políticos locais, ou seja, de uma demanda social.

Os enunciados, enquanto discurso, estão sujeitos a uma ordem; nela se prescreve o que pode ser dito, o que deve ser silenciado, submetido a regras de aparecimento e também suas condições de apropriação e de utilização, o que destaca desde sua existência a questão do poder, que é objeto de uma luta e de uma luta política.

Buscamos, na esteira de Foucault, compreender como o conceito de patrimônio, em São Luís, é talhado nos discursos da mídia local impressa.

As diretrizes de preservação do patrimônio sempre foram baseadas em uma seleção do que poderia ser resgatado e propagado como referência para o corpo coletivo. A priori, a seleção do que seria preservado instituiu os monumentos representativos da elite (igrejas, fortes militares, casarões de famílias nobres) como capazes de serem elementos dessa representação. Após esse momento a temática amplia-se e começa-se a considerar as formas de exposição da cultura como a melhor maneira de se preservar um legado. Assim, o patrimônio absorve as características, os ideais de cada época. O conceito muda de acordo com a suscetibilidade dos fatos que são institucionalizados pelo poder, ou seja, há uma técnica de poder que vai estabelecendo o conceito de patrimônio de acordo com a época. Não há, portanto, um sentido único para o patrimônio, pois ele é construído por tecidos discursivos que o materializaram na História; seu sentido é pura movência tramada pelos fatos históricos, e tem na mídia um mecanismo de divulgação desses diversos sentidos.

Segundo um enfoque genealógico, a construção do patrimônio, como acontecimento 
discursivo, é dada a partir da diversidade, da dispersão, de começos incidentais que não voltam ao tempo para restaurar a história em sua continuidade. Busca, entretanto, reconfigurar os acontecimentos em sua singularidade. A reconstituição de acontecimentos que estabelecem a noção de patrimônio e identidade, em São Luís, emerge em vários momentos: inicialmente, destaca-se a noção de Atenas Brasileira no discurso literário, que liga os costumes ludovicenses a uma cultura erudita; num segundo momento, destacam-se leis, documentos oficiais e fotográficos que cristalizam a noção de patrimônio a partir de um discurso sobre o salubrismo, a higienização; num terceiro momento, a disseminação das mídias, o deslocamento da cultura do âmbito elitista para o popular constroem uma simultaneidade de identidades que vai consolidar uma concepção pós-moderna de patrimônio.

Apresentamos, no espaço deste artigo, ainda que brevemente, o papel discursivo da mídia nesse processo. Vale lembrar que os jornais selecionados para análise são considerados de oposição (O Imparcial) e de direita (O Estado do Maranhão). Sendo assim, eles reproduzem formações discursivas que representam seu posicionamento perante a sociedade.

Em 06 de dezembro de 1997, São Luís recebeu o título de Patrimônio Cultural da Humanidade. Todavia, esse título é resultado de um longo processo, não somente no que tange à questão das intervenções físicas, mas também de ações políticas e de um fluxo de discursos propagados. O jornal O Estado do Maranhão (1997) exibiu a seguinte matéria, da qual apresentamos o seguinte trecho:

Presente à sessão da UNESCO na condição de chefe da delegação brasileira, em Nápoles, a governadora do Maranhão, Roseana Sarney, que se fez acompanhar do ex-presidente e senador José Sarney e pelo prefeito de São Luís Jackson Lago, comemorou o resultado de um projeto apresentado à UNESCO em maio do ano passado, em Paris. [...] o ex-presidente Sarney, citado pelo prefeito de Nápoles no discurso de encerramento da reunião, observou que São Luís foi a única cidade da América do sul a receber na ocasião, o reconhecimento oficial da UNESCO.

A outorga do título, em nível local, põe em evidência o tão falado discurso do patrimônio cultural. Um discurso que enquanto emergência representa a combinação de enunciados dentro de uma ordem discursiva que diz "o que", "como" e "onde" se deve dizer e o que se deve ocultar e obviamente articula uma função enunciativa, como também uma função-sujeito, enredados por uma economia de poder
(GREGOLIN, 2000). Os discursos assim produzidos trazem marcas da cena social considerada, expressam o modo como cada núcleo discursivo se posiciona no mercado simbólico e por meio de estratégias disputam a supremacia sobre os demais.

No excerto do jornal O Estado do Maranhão são destacadas as presenças da governadora do Maranhão (Roseana Sarney), que está acompanhada do ex-presidente e senador José Sarney. Destaca-se ainda a presença do prefeito de São Luís Jackson Lago. O jornal frisa que a governadora se faz presente em Nápoles na condição de chefe da delegação brasileira, menciona a referência que o prefeito de Nápoles faz ao ex-presidente Sarney em seu discurso e este, por sua vez, faz uso da palavra. Mas o jornal O Estado do Maranhão não menciona se o prefeito Jackson Lago também faz uso da palavra. A figura do prefeito é colocada de forma bem rápida, sugerindo que sua presença na cerimônia de outorga do título de cidade Patrimônio Cultural da Humanidade é apenas decorativa.

A palavra sempre foi um instrumento de poder no contexto histórico que insere o homem, por meio de um sistema de símbolos. É importante analisar como o discurso configura-se em um campo de confrontos teórico-metodológicos, ou seja, como um conjunto de métodos pode ser utilizado para analisar além da subjetividade, em que momento o sujeito deposita suas impressões, suas características pessoais na configuração dos discursos, enfim quando a impessoalidade é renegada a segundo plano. Como instrumento do discurso, ressalta-se a utilização da linguagem, da simbologia, da representatividade e da exterioridade como fatores condicionantes das formações discursivas. Percebe-se, então, a contextualização entre o linguístico e o histórico como elemento essencial para a análise do discurso do patrimônio cultural. É importante pensar sobre a utilização do patrimônio nas relações de poder, identificando quais agentes sociais se beneficiam com a utilização de uma prática discursiva legitimada.

Em São Luís, percebemos a exaltação do Patrimônio Cultural e sua utilização como símbolo de identidade social, no intuito de manobrar a grande massa em torno de um sentimento comum de "pertencimento". Essa coercitividade tem como objetivo primordial unificar uma sociedade em torno da utilização de um espaço físico como forma de atribuir signos e símbolos que unificam o coletivo. 
A mídia aqui é tomada como um meio de propagação de uma imagem a ser difundida na sociedade e como um meio de destacar determinados atores sociais. Segundo o jornal O Imparcial (1997):

Mal São Luís ingressou no seleto clube de sítios sob domínio da humanidade, as duas principais correntes políticas do Estado deram início a uma queda de braço ferrenha pela paternidade do título. O senador $\mathrm{Ca}$ feteira, numa jogada genial, aproveitou a brecha da legislação para colocar no horário nobre da TV, inclusive no canal da família Sarney, um filme mostrando os feitos do seu governo na área da Praia Grande que teria viabilizado a honrosa distinção. A governadora Roseana, por sua vez, usa todo o espaço da mídia, dando ênfase à homenagem, como uma conquista sua, em primeiro plano, e do povo do Maranhão em segundo.

Nesse excerto de O Imparcial, as formações discursivas revelam uma combinação de enunciados que ora revelam o "senador Cafeteira [que] numa jogada genial" aproveita a oportunidade para divulgar os "feitos de seu governo" na Praia Grande, destacando como seu papel "teria viabilizado a honrosa distinção" de Patrimônio Cultural da Humanidade, ora apontam como a governadora Roseana "usa todo o espaço da mídia, dando ênfase à homenagem, como uma conquista sua, em primeiro plano, e do povo do Maranhão em segundo." O jornal articula uma função enunciativa que se coloca no horizonte de um jornal de esquerda para dizer que o senador Cafeteira fez uso de uma "jogada genial" ao valer-se dos espaços da mídia (o jornal do Sistema Mirante de Comunicação, de propriedade da família Sarney) a fim de mostrar sua relevância para a articulação do título de Patrimônio Cultural da Humanidade, e põe a figura da governadora Roseana Sarney como alguém que toma para si uma conquista que é resultado de um conjunto de esforços (de outros governantes) e que também é do povo maranhense. Esse discurso revela uma luta pela hegemonia política da localidade.

Há, nesse sentido, uma ordem discursiva que ponta "o que" (o papel de cada um - Cafeteira e Roseana - na cena política maranhense), "como" (o dizer sobre esse papel: Cafeteira foi "genial" ao utilizar a mídia da família Sarney; Roseana coloca-se em primeiro plano e o povo em segundo) e "onde" (o jornal O Imparcial). A função enunciativa articulada, assim como a função-sujeito, falam do lugar da oposição.

A cidade de São Luís sempre está presente em um discurso constante de exaltação de seus qualitativos, ressaltando épocas, atores, espaços e colocando a sociedade em uma relação de forças, da qual a mesma é objeto e age de maneira subjetiva nas suas participações, haja vista que se torna um elemento conduzido nas práticas discursivas e também cotidianas. Nos discursos jornalísticos analisados entrelaçam-se a propagada celebração das características de pertencimento a uma cidade Patrimônio da Humanidade.

No Jornal O Estado do Maranhão, no Caderno "São Luís - Patrimônio da Humanidade", de 19 de dezembro de 1997, José Sarney, no texto: São Luís, poesia e cravo escreve o seguinte:

Deus quando fez o mundo, deixou para fazer o Maranhão no último dia, um lugar para ele descansar. [...] Deus aqui é pobre, não tem ouro nem prata, tem pedra e cal, com essas matérias fez ruas tão belas, espaços tão majestosos feitos de luz e de estrelas. [...] Aqui não se erguem estátuas a heróis e soldados, políticos e administradores. Somente a poetas e escritores.

Agora, São Luís é da humanidade. [...] São Luís é assim: o belo e o trágico estampados nas cimalhas, com suas mísulas entalhadas, capitéis de volutas, beirais duplos em telhas esmaltadas. Conheçam a cidade em que a lenda e a realidade andam de braços dados. Em cada esquina um sobradão reluzindo azulejos, a lembrar do tempo em que a arquitetura era arte.

\section{A herança se faz maior porque também decorre dos bens intelectuais, espirituais, morais e religiosos. [...] somos herdeiros do que pode haver de mais belo e mais precioso, que é a glória eternizada na memó- ria de um povo, a servir de exemplo para o mundo. (SARNEY, 1997).}

Vemos aí a construção de um discurso sobre a cidade ressaltando sua história, seus fazeres e saberes de forma poética; os problemas de toda ordem são esquecidos; projeta-se nesse discurso uma cidade que resguarda uma forma majestosa em um lugar perfeito para se viver. Até mesmo a pobreza é retratada como herança divina, e se não se realizam homenagens a políticos, então que estes sejam também escritores. E aqui vemos que o poeta Sarney inserido nessa homenagem.

A concepção de patrimônio, enquanto elemento evocativo da memória local e nacional, perpassa as ações preservacionistas, impondo um debate acerca do sentido e do significado que ele adquire no contexto de uma dada sociedade. Torna-se preponderante compreender que subjacente às tentativas de retorno ao passado mitológico, empreendidas pelos gestores estaduais e municipais, artistas, arquitetos e intelectuais coexiste um amálgama de interesses políticos, econômicos e valorativos imbricados na forma como os sujeitos concebem e interpretam o patrimônio e a memória digna de ser preservada. 
Nesse excerto do jornal O Estado do Maranhão há uma expressão de orgulho, ostentação das grandes riquezas e dos grandes feitos, numa demonstração de que o conceito de patrimônio é aquele que representa a elite; ele é forjado de pedra e cal (o patrimônio material), incrustado em "ruas tão belas, espaços tão majestosos feitos de luz e de estrelas". A capital São Luís "com suas mísulas entalhadas, capitéis de volutas, beirais duplos em telhas esmaltadas" é o retrato da riqueza de uma classe social numa época próspera e que deixou seus traços na arquitetura.

Para Pesavento (2004, p. 39), representações "são matrizes geradoras de condutas e práticas sociais, dotadas de força integradora e coesiva, bem como explicativa do real. Indivíduos e grupos dão sentido ao mundo por meio das representações que constroem sobre a realidade". Nessa visão, o patrimônio passa a ser visto como um sistema de representação de uma sociedade em uma determinada época. As narrativas de construção de uma identidade nacional, por exemplo, utilizam-se de construtos patrimoniais para enaltecer determinados elementos que são considerados importantes a uma determinada coletividade, na tentativa de impor uma identidade.

Nesse processo, a apropriação está subjacente à seleção de um elemento como patrimônio, pois é entendida:

\footnotetext{
como uma resposta necessária à fragmentação e à transitoriedade dos objetos e valores. Apropriar-se é sinônimo de preservação e definição de uma identidade, o que significa dizer, no plano das narrativas nacionais, que uma nação torna-se o que ela é na medida em que se apropria de seu patrimônio. (GONÇALVES, 2002, p.24).
}

Esse enunciado de $\mathrm{O}$ Estado do Maranhão faz um retorno ao passado condicionado pela memória e pelos exemplos de construções que perpetuam épocas: "somos herdeiros do que pode haver de mais belo e mais precioso, que é a glória eternizada na memória de um povo, a servir de exemplo para o mundo" num exercício de preservação de seu patrimônio e de sua identidade: a de um povo que pertence a uma cidade que "Agora [...] é da humanidade."

A construção de discursos sobre o patrimônio na cidade de São Luís emergiu numa tentativa de afirmação de múltiplas singularidades, e na busca pela preservação de marcos simbólicos imbuídos de um caráter de autenticidade. Por outro lado, a configuração de cidade-patrimônio reveste-se também na imposição de um imaginário social, ou seja, de "um sistema de idéias e imagens de representação coletiva que os homens, em todas as épocas, construíram para si, dando sentido ao mundo". (PESAVENTO, 2004, p.43).

As ações que tangem a questão do $\mathrm{Pa}-$ trimônio são marcadas por paradoxos e pela mídia que propaga os discursos individuais repletos de significados convenientes aos seus criadores. Essa prática social atribuída aos sentidos é uma esfera do espaço da hegemonia, que passa por formas de organizar, distribuir e selecionar ordens de discursos.

\section{CONSIDERAÇÕES FINAIS}

A análise de textos da mídia demonstra que o conceito de patrimônio, dentre outras coisas, emerge de um discurso que se articula a processos ideológicos, ora de um lugar de esquerda (que se reflete nos enunciados do jornal O Imparcial), ora no jornal de direita (que se manifesta linguisticamente nos enunciados do jornal O Estado do Maranhão). Dessa forma, há toda uma trama que se efetiva em práticas discursivas que apontam para o lugar de onde falam os sujeitos.

A análise da rede discursiva que abrange as práticas relacionadas ao Patrimônio Cultural é de extrema importância para compreendermos o processo que seleciona fatos, glorifica atos e promove atores sociais capazes de manobrar uma sociedade em torno de um vínculo identitário.

\section{NOTAS}

1. Para maiores detalhes, conferir CARVALHO, C. de M. B. A genealogia do patrimônio em São Luís: da Athenas à capital da diversidade. Araraquara, SP, 2009. Tese (Doutorado em Letras) - Universidade Estadual Paulista Júlio de Mesquita Filho. Programa de Pós-Graduação em Linguística e Língua Portuguesa. Disponível em: <portal.fclar. unesp.br/poslinpor/teses/ conceição_maria_belfort_carvalho.pdf>.

\section{REFERÊNCIAS}

FOUCAULT, M. Arqueologia do saber. Rio de Janeiro: Forense Universitária, 1986.

. Outros espaços. In: MOTA, M. B.

(Org.). Michel Foucault e a estética: literatura e pintura, música e cinema. Rio de Janeiro: Forense Universitária, 2001. v. 3, p. 411-422.

GONÇALVES, J. R. S. A retórica da perda: os discursos do patrimônio cultural no Brasil. 2. ed. Rio de Janeiro: UFRJ/ IPHAN, 2002. 
GREGOLIN, Maria do Rosário V. (Org.).

Filigranas do discurso: as vozes da história. Araraquara: FCL/Laboratório Editorial/ UNESP; São Paulo: Ed. Cultura Acadêmica, 2000.

O ESTADO DO MARANHÃO. São Luís, 4 dez. 1997.
O IMPARCIAL. São Luís, 17 dez. 1997.

PESAVENTO, S. J. História e história cultural. Belo Horizonte: Autêntica, 2004.

SARNEY, J. São Luís, poesia e cravo. $O$ Estado do Maranhão, São Luís, 19 dez. 1997. Caderno "São Luís - Patrimônio da Humanidade". 